\title{
The simulation tests of the flow in the device stabilizing the working pressure of the cement slurry
}

\author{
Lukasz Nowakowski ${ }^{1, *}$, Wojciech Depczyński ${ }^{2}$, Slawomir Blasiak ${ }^{3}$, \\ ${ }^{1}$ Chair of Mechanical Engineering and Metrology, Kielce University of Technology; Aleja Tysiąclecia Państwa Polskiego 7; 25-314 \\ Kielce; Poland, lukasn@tu.kielce.pl \\ 2 Department of Metal Science and Manufacturing Processes, Kielce University of Technology; Aleja Tysiąclecia Państwa Polskiego 7; \\ 25-314 Kielce; Poland,wdep@tu.kielce.pl \\ 3 Chair of Mechanical Engineering and Metrology, Kielce University of Technology; Aleja Tysiąclecia Państwa Polskiego 7; 25-314 \\ Kielce; Poland, sblasiak@tu.kielce.pl
}

\begin{abstract}
The article describes research carried out for design and construction of devices stabilizing the working pressure of cement slurry, with use of Deep Soil Mixing technology. The paper presents also the results of numerical calculations showing the flow in the device stabilizing the working pressure of the cement slurry. Flow simulation tests were carried out in the ANSYS program.
\end{abstract}

\section{Introduction}

The article presents the results of the simulation tests carried out in the Ansys Fluent environment of the cement slurry flow through the prototype of the pressurestabilizing device. The prototype of the pressurestabilizing device will be applied in the injection line to reinforce the weak or unstable foundation soil with the Deep Soil Mixing (DSM) technology [1-4]. The DSM technology involves making soil-cement mix columns in an unstable foundation soil (Fig. 1) [5]. Reinforcement of the foundation soil structure by making columns (cut-off walls) requires placing steel mixer or mixers in the foundation soil, usually rotating clockwise. At the same time, the cement slurry, the main components of which are water and cement, is fed under high pressure to the foundation soil, loosened by the mixers.

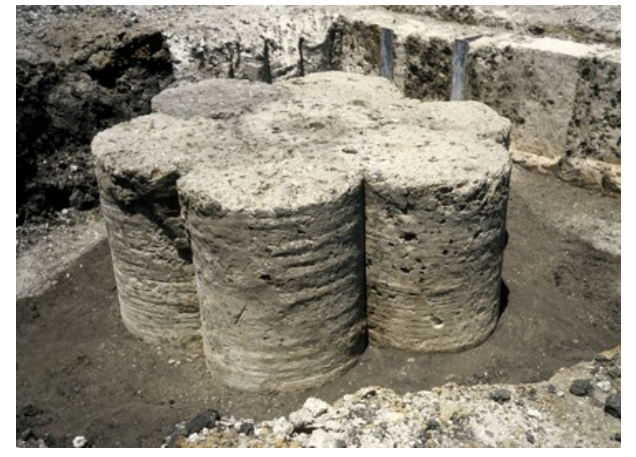

Fig. 1. The cut-off wall made in the DSM technology [5]

The cement slurry is usually fed into the line by an electric injection unit, which consists of two sand plunger pumps, often operating in double sets, the plungers of which operate alternately. The main disadvantage of plunger pumps in case of an injection system without a pressure-stabilizing device (pulsation dampener) is the pulsation of the pressed medium, which leads to damage to the injection ducts. Manufacturers of the injection units recommend using a pulsation dumper (compensator) at the unit outlet or on the discharge pipe of the dumper. Unfortunately, the currently manufactured design solutions of pulsation dampers are not adapted to cooperate with cement and bentonite slurries as they have a limited self-cleaning ability during continuous operation. A large amount of impurities in the damper chamber being the product of slurry sedimentation, which blocks the flow through the device, is the negative effect of this.

This article presents the findings of the simulation tests on the cement slurry flow through the prototype of a pressure-stabilizing device. The conducted tests were aimed at analysing how the design solutions applied in the device affect its ability to self-clean the working surface of the chamber during operation.

\section{Subject of Tests}

The subject of the tests was the pulsation damper prototype for reduction of pulsation pressure of cement and bentonite slurries, the design of which allows continuous cleaning of the internal surfaces of the cylinder during its operation [6].

The principle of operation of the pressure-stabilizing device is that the cement slurry, (Fig. 2) pressed by the plunger pump, is fed to the inlet 14 of the pulsation damper located in the sleeve 13 . Then, the liquid flows through the pipe 15 and the nozzle 16 , filling the chamber 11 under the press 9 . The main task of the nozzle 16 is to mix, mould and canalize the liquid stream so as to rinse the inner walls of the cylinder 4 and set the elastic element 12 in extra vibrations that will intensify the process of mechanical cleaning of the inner surfaces of the cylinder

\footnotetext{
$\overline{\text { * Corresponding author: lukasn@tu.kielce.pl }}$
} 
4. The change in pressure caused by the operation of the pump acts on the press 9 , which moves axially up and down along the cylinder axis 4 . The change in the position of the press 9 caused by the change in the volume of the lower chamber 11 , relative to the upper chamber 10 , suppresses the pulsation of the pressed cement slurry by compressing and decompressing the gas in the chamber 10 above the press 9 . The press 9 moving up and down sets the elastic element 12 in motion, the edges of which rub against the inner surface of the cylinder 4, mechanically cleaning its surface.
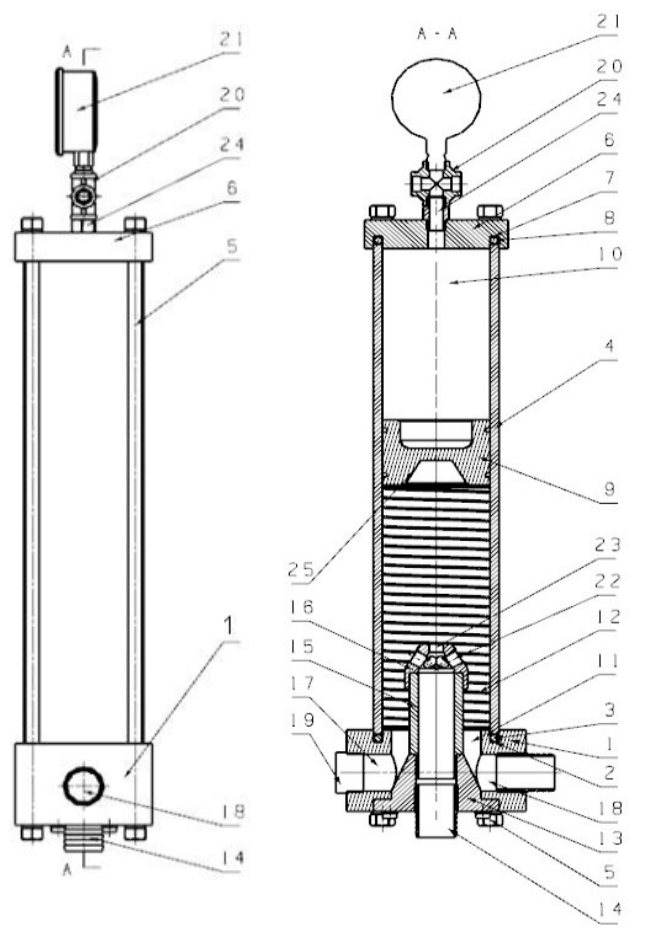

Fig. 2. Pressure-stabilizing device [8]: 1 - body, 2 - annular groove, 3 - rubber ring 4 - cylinder, 5 - connecting bolts, 6 - head, 7 - annular groove, 8 - O-ring, 9 - press, 10 - chamber above the press, 11 - chamber under the press 12 - elastic element, 13 conical sleeve, 14 - inlet, 15 - pipe. 16 - nozzle, 17 - inspection hole, 18 - outlet, 19 - plug, 20 - cross, 21 - manometer, 22, 23 nozzle openings, 24 - connector, 25 - socket.

\section{Methods}

It was assumed in the conducted simulation tests that the cement slurry will be fed by the AIE-400 electric injection unit produced by the BIPROMASZ. The AIE-400 injection unit (Fig. 3) is equipped with two PPN - 250 sand plunger pumps operating in double sets.

The parameters of the plunger pumps are included in the table 1 [7].

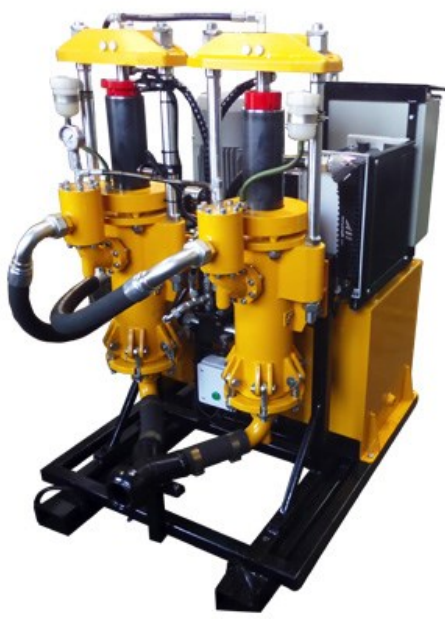

Fig. 3. AIE injection unit [7]

Table 1. Parameters of the AIE-400 injection unit

\begin{tabular}{|c|c|}
\hline Plunger pump & PPN-250- 2 pcs \\
\hline Injection grout & Cement and bentonite slurries \\
\hline Performance per one cycle & $4.6 \times 2 \mathrm{dm}^{3}$ \\
\hline $\begin{array}{c}\text { Performance in the AIE- } \\
400 \text { set }\end{array}$ & up to $400 \mathrm{dm}^{3} / \mathrm{min}$ \\
\hline Maximum pressure & $4(6$ for micropiles) MPa \\
\hline Drive & $50 / 36 \times 250 \mathrm{AH}$ Actuator \\
\hline Pump output & $400 \mathrm{~L} / \mathrm{min}$ \\
\hline Pump type & Single Acting \\
\hline Number of pump cycles & 53 per min. \\
\hline Number of cylinders & $2 \mathrm{pcs}$ \\
\hline Forcing pressure & $40 \mathrm{Bar}$ \\
\hline Residual pulsation & $8.1 \%$ \\
\hline
\end{tabular}

Knowing the characteristics of the injection unit powering the device stabilizing the pressure of the cement slurry, it was described by the equation shown in fig. 2 . Then, the proper tests began after identifying the flow parameters $[8,9]$. In the first stage, a three-dimensional geometric model of the pressure-stabilizing device corresponding to the actual design was developed using the CAD environment. Next, discretization of the calculated field was carried out by selecting the type and resolution of the grid. A triangle shaped grid was applied fig. 5, which was compressed in places with large gradients. Total number of elements was 31707 at 25904 nodes. It was the minimum number of cells at which no significant effect of the increase in grid density on the final result was found.

The parameters of a fluid put on in CFD simulation are included in the table 2.

Table 2. Parameters of a fluid

\begin{tabular}{|c|c|}
\hline Cement slurry & non-Newtonian fluid \\
\hline Density & $1453\left[\mathrm{~kg} / \mathrm{m}^{3}\right]$ \\
\hline Pressure range & $3.2-4.8[\mathrm{MPa}]$ \\
\hline Temperature & Constant \\
\hline
\end{tabular}




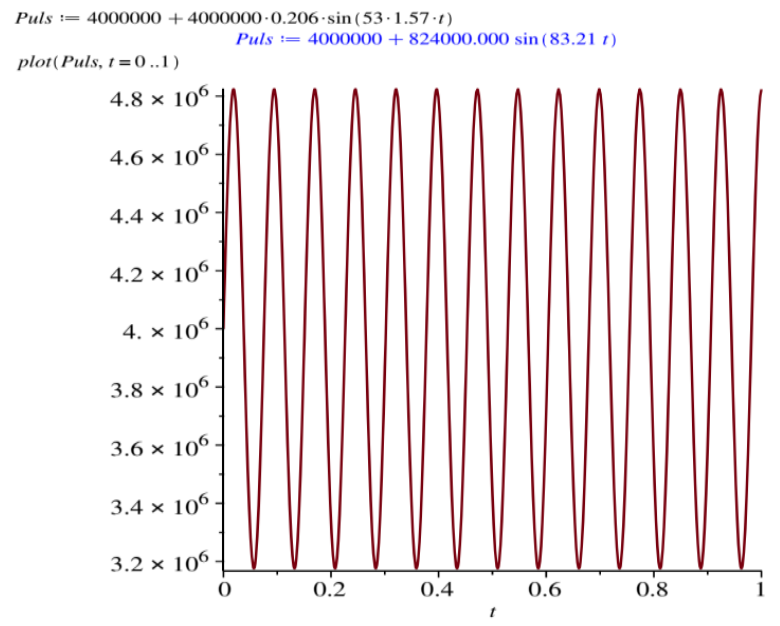

Fig. 4. Equation and graph showing pulsation of the cement slurry a)

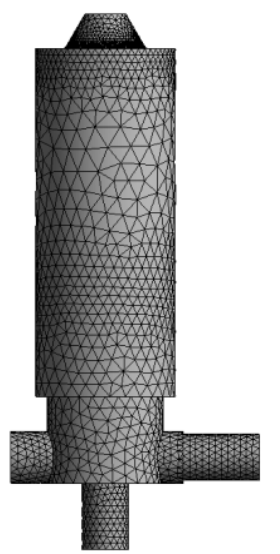

b)

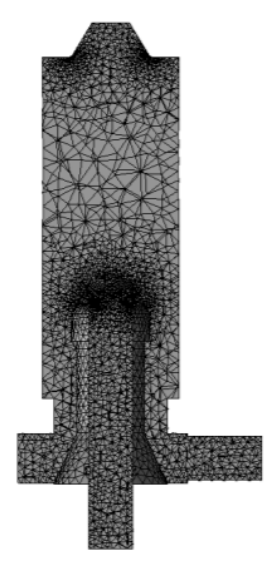

Fig. 5. Discretization of the calculated field of the tested object: a) external, b) internal

The CFD tests were performed using the Ansys Fluent software. Due to the research issues being undertaken, tests were carried out for the start-up phase of the device in 0 s to $0,1 \mathrm{~s}$.

\section{Results of CFD modelling}

Fig. 6 shows distributions of pressure fields during the start-up of the pressure-stabilizing device corresponding to the individual moments of time t: $0.025 \mathrm{~s} ; 0.05 \mathrm{~s} ; 0.075$ $\mathrm{s} ; 0.1 \mathrm{~s}$. Analysing the results from the simulation tests, it was found that the solutions adopted at the design stage of the pressure-stabilizing device enable the self-cleaning of the lower chamber of the device, cleaning off sedimentation products of cement slurry. A thorough analysis of the half-pressure distribution showed a significant pressure drop across the nozzle 16 and revealed vacuum at outlet 14 from the pressure-stabilizing device. In connection with a significant pressure drop at the nozzle, it will be necessary to optimize the shape of the nozzle, including the number and size of openings and their dimension. The occurrence of vacuum at the cement slurry outlet from the pressure-stabilizing device can lead to cavitation, which is undesirable and may lead to accelerated wear and may emit noise. Therefore, it is required to optimize the shape of the device body in order to minimize or eliminate the occurrence of vacuum. a)

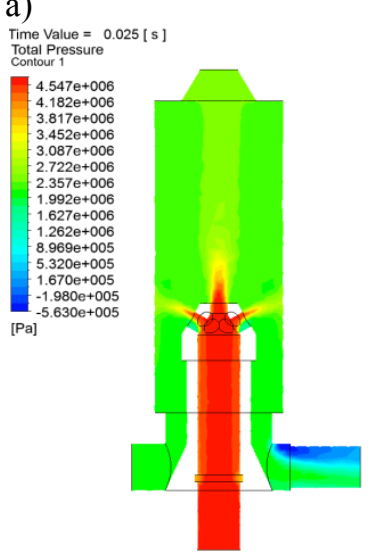

c)

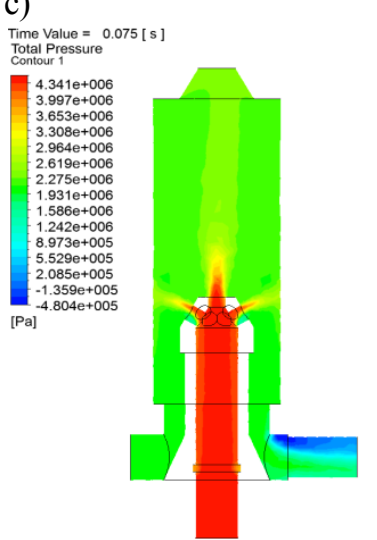

b)

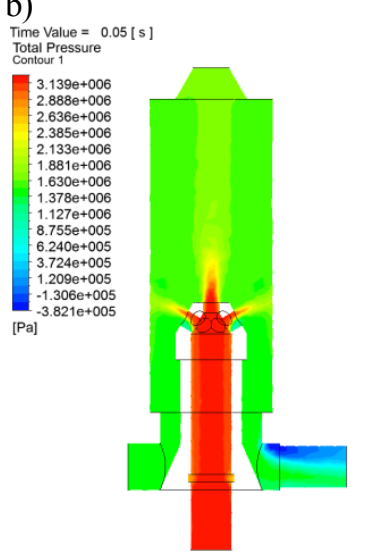

d)

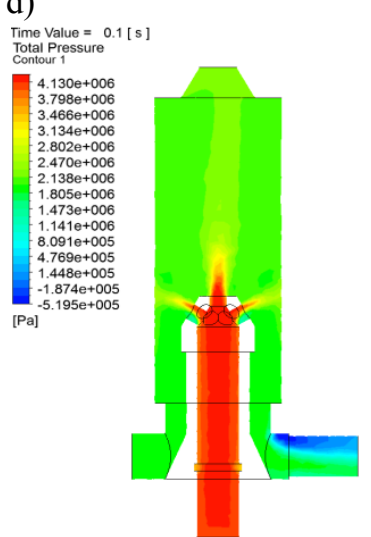

Fig. 6. Distribution of pressure fields for particular times: a) $0.025 \mathrm{~s}$; b) $0.05 \mathrm{~s}$; c) $0.075 \mathrm{~s}$; d) $0,1 \mathrm{~s}$

Fig. 7 shows the velocity vector distribution of cement slurry in the chamber 11 under the press 4 during the startup of the pressure-stabilizing device corresponding to the individual times $0.025 \mathrm{~s} ; 0.05 \mathrm{~s} ; 0.075 \mathrm{~s} ; 0,1 \mathrm{~s}$. The analysis of the velocity vector distribution of the cement slurry flowing out of the nozzle 16 allowed to evaluate the ability of the device to self-clean the cylinder surface 4, the lower surface of the press 9 and the outlet of the pressure stabilizing-device. Analysing the velocity vector distribution shown in Figure 7, we can observe how the cement slurry flowing out from the axial outlet of the nozzle 16 rinses the bottom surface of the press 9 cleaning it, while the outlets of the nozzle 16 , distributed radially and at an angle, direct the stream of the cement slurry to the surface of the cylinder and clean off sedimentation products of the cement slurry. The analysis of the velocity vector distribution in the lower chamber showed that there is virtually no flow on the left side where the inspection plug 19 is located, which may cause deposition of impurities here. The cement slurry will not be rinsed out from this area. In this case, the proposed solution is to eliminate the plug 19, what will create a second outlet here. Applying such a solution will require the use of a double duct, but will significantly improve the selfcleaning ability of the device. 
a)

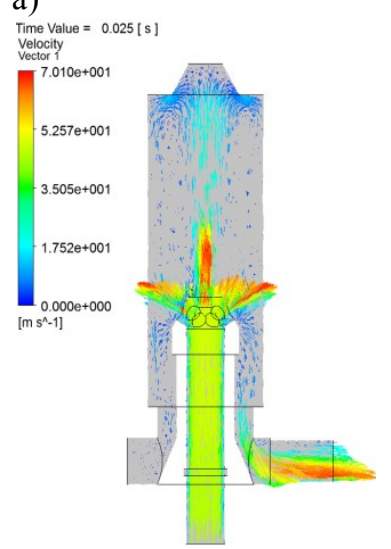

c)

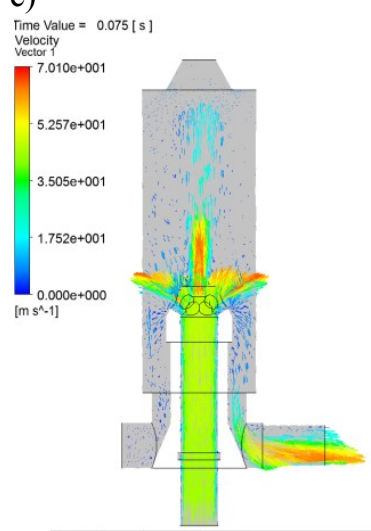

b)

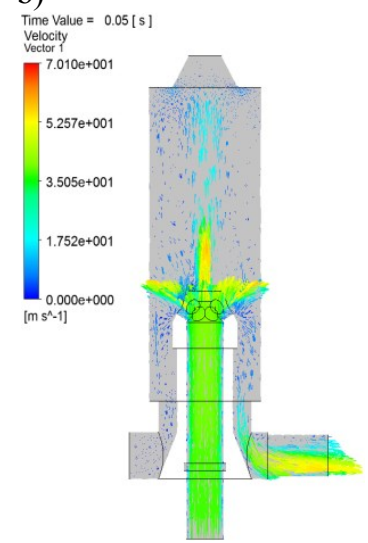

d)

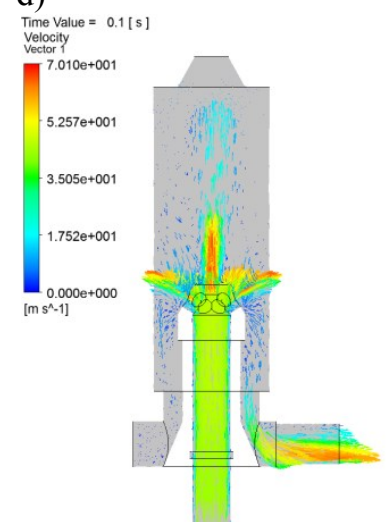

Fig. 7. The velocity vector distribution for particular times: a) $0.025 \mathrm{~s}$; b) $0.05 \mathrm{~s}$; c) $0.075 \mathrm{~s}$; d) $0,1 \mathrm{~s}$

\section{Summary}

The tests, performed in the ANSYS FLUENT environment, analysed the flow of the cement slurry through the prototype of the pressure-stabilizing device and allowed to formulate the following conclusions:

1. The design solutions, adopted at the design stage of the pressure-stabilizing device, implement the selfcleaning process of the lower chamber of the device, cleaning off sedimentation products of cement slurry.

2. The analysis of the half-pressure distribution showed a significant pressure drop across the nozzle and revealed vacuum at outlet from the pressurestabilizing device.

3. The occurrence of vacuum at the outlet of a cement slurry from the pressure-stabilizing device can lead to cavitation.

4. In connection with a significant pressure drop at the nozzle, it will be necessary to optimize its design.

5. In order to minimize or eliminate the occurrence of vacuum, it is necessary to optimize the body of the device.

6. The analysis of the velocity vector distribution in the lower chamber showed that there is virtually no flow on the left side, which may cause deposition of impurities here.

7. The analysis of the velocity vector distribution showed that the cement slurry flowing out of the nozzle outlets rinses the bottom surface of the press and the surface

of the cylinder, cleaning off sedimentation products of the cement slurry.

The construction of the pressure-stabilizing device was implemented as part of the project titled "Nowoczesne $i$ innowacyjne technologie iniekcji gruntów (Modern and innovative soil injection technologies)" co-financed from European Funds. The project is implemented by EKOKANWOD Czyszczoń i Póltorak sp.j.

: Fundusze
Europejskie
Program Regional
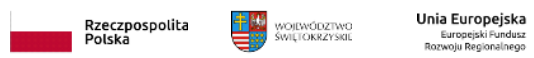

\section{References}

1. A. Egorova, J. Rybak, D. Stefaniuk, P. Zajączkowski, IOP Conference Series: Materials Science and Engineering 245. (2017)

2. M.Topolnicki, XXIV Geotechnical Conference of Torino Design, Construction and Controls of Soil Improvement Systems, Torino, (2016)

3. Y. Zaika, A. Rachmansyah, International Journal of GEOMATE, 13, 38, (2017)

4. G.A. Pittaro, Geotechnical Engineering, 48, 2, (2017),

5. https://www.raitoinc.com/technologies/multiauger-soil-mixing/

6. Ł. Nowakowski, W. Depczyński; Pressure pulsation damper patent aplication P.424788, (2018)

7. Plunger pumps manual AIE-400 (2017)

8. Z. Kudźma Suppression of pressure and noise pulsations in hydraulic systems in transient and established states, OWPW (2012)

9. S. Blasiak, Int. J. Heat Mass Transfer 100, 79 (2016) 